\title{
Rapidly increasing macroalgal cover not related to herbivorous fishes on Mesoamerican reefs
}

Adam Suchley, Melanie D McField, Lorenzo Alvarez-Filip

Long-term phase shifts from coral to macroalgal dominated reef systems are welldocumented in the Caribbean. Although the impact of coral diseases, climate change and other factors is acknowledged, major herbivore loss through disease and overfishing is often assigned a primary role. However, direct evidence for the link between herbivore abundance, macroalgal and coral cover is sparse, particularly over broad spatial scales. In this study we use a database of coral reef surveys performed at 85 sites along the Mesoamerican Reef of Mexico, Belize, Guatemala and Honduras, to examine potential ecological links by tracking site trajectories over the period 2005-2014. Despite the longterm reduction of herbivory capacity reported across the Caribbean, the Mesoamerican reef region displayed relatively low macroalgal cover at the onset of the study.

Subsequently, increasing fleshy macroalgal cover was pervasive. Herbivorous fish populations were not responsible for this trend as fleshy macroalgal cover change was not correlated with initial herbivorous fish biomass or change, and the majority of sites experienced increases in macroalgae browser biomass. This contrasts the coral reef topdown herbivore control paradigm and suggests the role of external factors in making environmental conditions more favourable for algae. Increasing macroalgal cover typically suppresses ecosystem services and leads to degraded reef systems. Consequently, policy makers and local coral reef managers should reassess the focus on herbivorous fish protection and consider complimentary measures such as watershed management in order to arrest this trend. 


\section{Rapidly increasing macroalgal cover not related to herbivorous fishes \\ 2 on Mesoamerican reefs}

3

4 Adam Suchley ${ }^{1,2}$, Melanie D. McField ${ }^{3}$ \& Lorenzo Alvarez-Filip ${ }^{2}$

5 1Posgrado en Ciencias del Mar y Limnología, Instituto de Ciencias del Mar y Limnología, Universidad

6 Nacional Autónoma de México, Mexico City, Mexico

7 2Unidad Académica de Sistemas Arrecifales, Instituto de Ciencias del Mar y Limnología, Universidad

8 Nacional Autónoma de México, Puerto Morelos, Quintana Roo, Mexico

93 Healthy Reefs for Healthy People Initiative, Smithsonian Institution, Ft Lauderdale, Florida, USA

11 Corresponding Author:

12 Lorenzo Alvarez-Filip²

13 Unidad Académica de Sistemas Arrecifales, Puerto Morelos, ICML, UNAM, Prol. Av. Niños Héroes S/N,

14 Domicilio conocido, C.P. 77580, Puerto Morelos, Quintana Roo, Mexico

15 Email address: lorenzo@cmarl.unam.mx 


\section{Abstract}

18 Long-term phase shifts from coral to macroalgal dominated reef systems are welldocumented in the Caribbean. Although the impact of coral diseases, climate change

20 and other factors is acknowledged, major herbivore loss through disease and

21 overfishing is often assigned a primary role. However, direct evidence for the link

22 between herbivore abundance, macroalgal and coral cover is sparse, particularly over

23 broad spatial scales. In this study we use a database of coral reef surveys performed at

2485 sites along the Mesoamerican Reef of Mexico, Belize, Guatemala and Honduras, to 25 examine potential ecological links by tracking site trajectories over the period 2005-

26 2014. Despite the long-term reduction of herbivory capacity reported across the

27 Caribbean, the Mesoamerican reef region displayed relatively low macroalgal cover at 28 the onset of the study. Subsequently, increasing fleshy macroalgal cover was pervasive.

29 Herbivorous fish populations were not responsible for this trend as fleshy macroalgal 30 cover change was not correlated with initial herbivorous fish biomass or change, and

31 the majority of sites experienced increases in macroalgae browser biomass. This

32 contrasts the coral reef top-down herbivore control paradigm and suggests the role of 33 external factors in making environmental conditions more favourable for algae.

34 Increasing macroalgal cover typically suppresses ecosystem services and leads to 35 degraded reef systems. Consequently, policy makers and local coral reef managers 36 should reassess the focus on herbivorous fish protection and consider complimentary 37 measures such as watershed management in order to arrest this trend. 
40 Caribbean coral reefs have experienced major declines over recent decades, with

41 substantial reductions in live coral cover accompanied by concomitant losses in reef

42 accretion and structural complexity (Schutte, Selig \& Bruno, 2010; Alvarez-Filip et al.,

43 2011; Perry et al., 2015). Although a wide array of factors have contributed to reef

44 deterioration including coral diseases, coastal development and climate change, the

45 loss of key herbivores is thought to be a leading driver of ecosystem transition towards

46 macroalgal domination at many reef sites in the region (Hughes, 1994; Jackson et al.,

47 2014). Macroalgae compete with corals, reducing coral fecundity, recruitment and

48 survival via various mechanisms including overgrowth, shading and allelopathy

49 (McCook, Jompa \& Diaz-Pulido, 2001; Hughes et al., 2007; Bruno et al., 2009; Rasher

50 et al., 2011). Today, populations of key herbivore taxa are diminished on many

51 Caribbean reefs. The sea urchin Diadema antillarum was previously an important grazer

52 in the Caribbean (Jackson et al., 2001). In 1983/4 Diadema suffered mass mortality

53 across the Caribbean due to putative disease and populations have subsequently

54 shown only limited recovery (Lessios, Robertson \& Cubit, 1984; Kramer, 2003; Hughes

55 et al., 2010). Furthermore, long-term overfishing has resulted in marked reductions in

56 herbivorous fish populations at many sites across the region (Jackson et al., 2001;

57 Paddack et al., 2009).

58 Given the pivotal role of herbivores in controlling macroalgal growth (Mumby et al.,

59 2006), it is widely accepted that restoring populations of key herbivores enhances reef

60 resilience by controlling algal communities and facilitating coral recovery by freeing

61 space for coral recruits (Nyström, Folke \& Moberg, 2000; McCook, Jompa \& Diaz- 
62 Pulido, 2001; McManus \& Polsenberg, 2004; Bruno et al., 2009). Consequently, coral

63 reefs with high herbivore abundance are expected to have lower macroalgal cover and

64 greater coral cover (Jackson et al., 2014; Kramer et al., 2015). This paradigm has

65 encouraged global awareness campaigns promoting conservation and fisheries

66 management strategies to protect and restore populations of key herbivorous fishes,

67 particularly parrotfishes (Jackson et al., 2014). In the Mesoamerican region, for

68 example, Belize and Guatemala have banned the capture and possession of

69 herbivorous fishes (Kramer et al., 2015).

70 Direct evidence of herbivores' ability to facilitate the maintenance and recovery of

71 resilient coral reefs is limited. Experimental herbivore exclusion studies demonstrate the

72 action of Diadema and herbivorous fish grazing on macroalgal cover, although evidence

73 for the impact on corals is limited by the short-term nature and restricted spatial extent

74 of the experiments (Lirman, 2001; Burkepile \& Hay, 2006, 2009; Hughes et al., 2007).

75 Observational studies tend to focus on inter-site comparisons without an explicit

76 temporal dimension, rather than tracking long-term reef change trajectories to provide a

77 more in-depth understanding of drivers of ecosystem dynamics (Karr et al., 2015). Little

78 consensus exists between studies, which exhibit contrasting patterns between

79 herbivorous fish populations and macroalgal cover. In a Caribbean-wide point-in-time

80 study, Newman et al. (2006) found a significant negative correlation between

81 herbivorous fish biomass and fleshy algal biomass, whereas Loh et al. (2015) observed

82 that overfished Caribbean sites had lower macroalgal cover than protected sites. For

83 the Northern Mesoamerican Reef of Mexico, Bozec et al. (2008) did not observe a

84 relationship between herbivore biomass and macroalgal cover. In a long-term study, 
85 Ilves et al. (2011) observed increases in both herbivorous fish abundance and algal 86 cover in the Bahamas. On the Northern Florida Reef Tract, Lirman \& Biber (2000)

87 observed no correlation between algal biomass and cover and fish grazer abundance 88 and consumption rates. Jackson et al. (2014) found a significant negative correlation 89 between parrotfish biomass and macroalgal cover in 16 Caribbean locations, however 90 no such relationship was observed for a broader data set covering 46 locations. The 91 lack of relationship between herbivorous fish and macroalgal cover is evident for other 92 regions: Carassou et al. (2013), for example, found that macroalgal cover was not 93 correlated with the biomass, density and diversity of macroalgae feeders in the South 94 Pacific.

95 To further understand the relationship between herbivory pressure and changes in 96 macroalgal cover we propose a simple conceptual framework (Fig. 1). Here, reefs may 97 experience one of four scenarios of temporal changes in fleshy macroalgal cover and 98 herbivorous fish biomass, a widely used proxy for herbivory intensity (Graham et al., 99 2015). Principal ecological drivers are presented for each idealised scenario, although 100 in reality a number of drivers act in conjunction to varying extents. A phase shift from 101 coral to algae domination due to herbivore loss is represented by the scenario in the 102 upper-left quadrant. Here, decreasing herbivory leads to increasing macroalgal cover. 103 Conversely, in the bottom-right quadrant, increases in herbivorous fishes result in 104 reduced macroalgal cover. This quadrant represents the scenario sought by 105 management measures and fisheries regulations restricting extraction, particularly of 106 herbivorous fishes (Halpern, 2003; Lester et al., 2009; Selig \& Bruno, 2010; Guarderas, 107 Hacker \& Lubchenco, 2011). 
108 Alternatively, a positive relationship may exist between macroalgal cover and

109 herbivorous fish biomass, as represented by the scenarios of the upper-right and

110 bottom-left quadrants of Fig. 1. This may occur when herbivores are food limited, as

111 evidenced by increases in herbivore abundance and biomass following algal growth and

112 by resource competition between Diadema and herbivorous fishes (Hay \& Taylor, 1985;

113 Carpenter, 1990; Adam et al., 2011). In these scenarios, predominantly external drivers

114 such as nutrient availability, temperature and solar irradiance determine macroalgal

115 cover and herbivorous fish biomass responds according to food availability (Burkepile \&

116 Hay, 2006; Ferrari et al., 2012). Numerous experimental manipulation studies have

117 reported the significant positive impact of nutrient enhancement on primary producer

118 abundance, although herbivory has generally been found to play a greater role

119 (Burkepile \& Hay, 2006). Contrastingly, few studies have addressed the importance of

120 macroalgal productivity potential relating to environmental factors such as light

121 availability and temperature (Steneck \& Dethier, 1994; Ferrari et al., 2012).

122 Herbivore and algal community composition also play an important role in herbivore123 algal dynamics. Subsequent to the Diadema mass mortality event of the early 1980's, 124 herbivorous fishes of the Scaridae and Acanthuridae families are recognised as the 125 primary herbivores on many Caribbean reefs (Jackson et al., 2014; Adam et al., 2015a).

126 While common Acanthurus surgeonfishes have a broad diet feeding on a combination

127 of turf algae, macroalgae and detritus, Sparisoma and Scarus parrotfishes are more 128 selective (Burkepile \& Hay, 2011; Adam et al., 2015a). Sparisoma parrotfishes, with the 129 exception of the excavating S. viride, are macroalgae browsers, while Scarus spp.

130 primarily graze algal turfs (Bonaldo, Hoey \& Bellwood, 2014; Adam et al., 2015b). 
131 Consequently, a suitable mix of herbivores are required in order to both graze turf algae

132 to facilitate coral recruitment and to crop down macroalgal stands to reduce competition

133 with adult coral colonies (McCook, Jompa \& Diaz-Pulido, 2001; Hughes et al., 2007;

134 Burkepile \& Hay, 2008). However, herbivores' ability to effectively moderate macroalgal

135 cover is mediated by macroalgal predation defences (Rasher, Hoey \& Hay, 2013). Such

136 defences are species specific and include morphological, structural, mineral and

137 chemical traits that deter herbivores, with several genera (e.g. Lobophora, Peyssonnelia

138 and Codium) being unpalatable (Hay, 1997; Smith, Hunter \& Smith, 2010). These

139 defences likely influence herbivore feeding preferences and conversely algal community

140 structure is often influenced by herbivore mix, resulting in a complex interaction

141 between the two communities (Adam et al., 2015a).

142 Here, by following individual site trajectories, we examine the prevalence of the four

143 herbivorous fish and macroalgae change scenarios across 85 sites surveyed from 2005

144 to 2014 along the Mesoamerican Reef. We also consider herbivore functional group

145 composition and trajectories, and compare these with overall trends. Subsequently, we

146 evaluate the potential effects of herbivorous fish biomass, fleshy macroalgal cover and

147 other factors such as degree of protection, on changes in coral cover during the same

148 timeframe. Our hypothesis is that for sites where herbivory increased, fleshy macroalgal

149 cover decreased, and that herbivore biomass and the decline in macroalgal cover are

150 among the main factors explaining coral cover on today's reefs. 
153 We used data produced by the Healthy Reefs Initiative (HRI) and the Atlantic and Gulf

154 Rapid Reef Assessment (AGRRA) programs, which include ecological censuses for 398

155 sites along the Mesoamerican Reef in Mexico, Belize, Guatemala and Honduras from

1562005 to 2014 . Site selection was based on benthic habitat maps produced by the

157 Millennium Reef Mapping Program, with $200 \mathrm{~m} \times 200 \mathrm{~m}$ sites randomly selected

158 following stratification by geomorphological characteristics and depth (Andréfouët et al.,

159 2003; Kramer, 2003). The database contains 85 long-term monitoring sites that were

160 surveyed in 2005/2006 and 2013/2014 over a 7, 8 or 9-year period, a timeframe

161 sufficient to observe ecologically meaningful changes (Babcock et al., 2010). Of these

162 sites, 43 were repeatedly surveyed in four time periods (2005/2006, 2009/2010,

$1632011 / 2012$ and 2013/2014). Sites were located primarily on the fore reef and reef crest

164 at a mean $( \pm$ Standard Error s.e.m. $)$ depth of $6.9 \pm 0.2 \mathrm{~m}$.

165 Benthic cover and reef fish surveys were performed according to AGRRA protocol, with 166 transects located haphazardly, parallel to the coast (Lang et al., 2010). The majority of

167 sites were surveyed at similar times during the summer year-on-year in order to

168 minimise seasonal effects. At each site an average of five to six $10 \mathrm{~m}$-transects were 169 surveyed using point intercept methodology to determine benthic cover including hard 170 coral percentage cover and fleshy macroalgal percentage cover. The abundance and 171 total length (TL) of 81 key reef fish species, including herbivorous fishes of the Scaridae

172 and Acanthuridae families, was recorded in ten 30 m-long, 2 m-wide transects. Reef fish

173 abundance was subsequently converted to biomass density using standard allometric

174 length-weight conversions. 
175 The data analyses focussed on the relation between three ecological indicators for each

176 reef site: herbivorous fish (Scaridae and Acanthuridae) biomass, fleshy macroalgal

177 (excluding turf and calcareous algae) cover and hard coral (scleractinians and Millepora

178 spp.) cover. Very few Diadema spp. were observed and therefore we focussed on reef

179 fishes as the principal herbivores. For all three ecological indicators, a number of

180 metrics were calculated to evaluate and examine temporal trends: absolute annual

181 change, annual relative rate of change and geometric rate of change. The metrics for

182 each ecological indicator $(I)$ were determined as follows:

$183 I_{\text {Absolute Annual Change }}=\frac{\left(I_{t_{f}}-I_{t_{0}}\right)}{\Delta t}$

$184 I_{\text {Annual Relative Rate of Change }}=\frac{\left(I_{t_{f}}-I_{t_{0}}\right)}{I_{t_{0}} \times \Delta t}$

$185 I_{\text {Annual Geometric Rate of Change }}=\left(\frac{I_{t_{f}}}{I_{t_{0}}}\right)^{\frac{1}{\Delta t}}-1$

186 where $I_{t_{f}}$ is the value of the ecological indicator at the end of the period, $I_{t_{0}}$ is the initial

187 value and $\Delta t$ is the length of the period (in years). The former two metrics provide

188 complementary information, for example: if an ecological indicator such as coral cover

189 increases from $10 \%$ to $15 \%$, the absolute change (equation (1)) is $5 \%$, while the

190 relative rate of change (equation (2)) indicates that coral cover has increased by $50 \%$

191 relative to its initial value. Geometric rate of change (equation (3)) was utilised in order

192 to assess and compensate for non-linearity in the relative rate of change, while still

193 providing an interpretable value (Côté et al., 2005). 
194 Univariate comparison of ecological indicators was performed using ANOVA, t-tests or 195 non-parametric equivalents (Mann-Whitney U or Wilcoxon Signed Rank tests), based 196 on an assessment of normality and homogeneity of variance using Shapiro-Wilk and

197 Levene tests. To test our first hypothesis, herbivorous fish biomass was compared with 198 fleshy macroalgal cover using Spearman rank-order correlation due to non-normality.

199 Herbivorous fishes were further categorised according to feeding preferences as 200 macroalgae browsers (Sparisoma spp., with the exception of S. viride), turf grazers / 201 scrapers (Scarus spp. and Acanthurus spp.) or bioeroders (Sparisoma viride) (Bellwood 202 et al., 2004; Burkepile \& Hay, 2011; Bonaldo, Hoey \& Bellwood, 2014; Adam et al., $2032015 a, b)$. Change in functional group biomass was compared with overall change in 204 herbivorous fish biomass using Spearman rank-order correlation. Furthermore, change 205 in macroalgal cover was compared with absolute levels of overall herbivorous fish and 206 macroalgae browser biomass both graphically by categorising sites by initial fish 207 biomass (based on deciles) and by using Spearman rank-order correlation.

208 To test our second hypothesis, change in absolute coral cover from 2005/6 to 2013/4 for 209 long-term monitoring sites was modelled using multiple linear regressions as model 210 assumptions were satisfied. To address the common problem of spatial autocorrelation 211 in multi-site studies we performed a Moran's I test on coral cover change by site 212 location which reported no spatial autocorrelation present (Moran's I $=0.070, P=0.08$ ). 213 The optimum regression model was selected based on Akaike Information Criterion 214 (AIC). Candidate independent variables were selected based on ecological relevance 215 and data availability (Table S1). Potential collinearity among predictor variables was 216 examined using Pearson correlations and variance inflation factors, and outliers were 
217 removed on the basis of Cook's $D$. All statistical analyses were performed using $R(R$

218 Core Team, 2014).

219

220 Results

221 Here we present herbivorous fish biomass and fleshy macroalgal cover average trends

222 for repeatedly surveyed sites and assess changes in these variables for long-term

223 monitoring sites. Subsequently we examine herbivorous fish feeding guilds and

224 geographic trends for long-term monitoring sites, and assess the effect of protection on

225 site trajectories. Finally we present the ecological drivers of long-term coral cover

226 change.

227 Herbivorous fish biomass and macroalgal cover trends

228 During the time period 2005 to 2014 , regional averages showed a clear trend of

229 increasing fleshy macroalgal cover on the Mesoamerican Reef, while herbivorous fish

230 biomass remained relatively constant. Across 43 sites surveyed repeatedly in four time

231 periods (Fig. 2), mean herbivorous fish biomass did not change significantly (Wilcoxon

232 Signed Rank, $Z=0, P=1$ ), while mean macroalgal cover doubled during the same

233 period (Wilcoxon Signed Rank, $Z=-5.02, P<0.001$ ). Between 2005/2006 and

234 2009/2010 mean herbivorous fish biomass decreased and mean fleshy macroalgal

235 cover increased significantly (Wilcoxon Signed Rank, $Z=3.36, P<0.001$ and $Z=-3.86$,

$236 \mathrm{P}<0.001$, respectively). From $2009 / 10$ to $2011 / 12$ the trend appeared to be reversed,

237 although the changes were not significant for macroalgae (Wilcoxon Signed Rank, Z = - 
$2382.95, P=0.003$ and $Z=0.59, P=0.55$, respectively; Fig. 2). From 2011/2012 to

239 2013/2014 macroalgal cover increased significantly, while herbivorous fish biomass

240 remained unchanged (Wilcoxon Signed Rank, $Z=-3.81, P<0.001$ and $Z=-0.35, P=$

2410.73 , respectively; Fig. 2).

242 Tracking individual trajectories of the 85 long-term monitoring sites surveyed over a 7, 8

243 or 9-year period permitted a more detailed investigation of the relation between the

244 temporal changes in herbivorous fish biomass and fleshy macroalgal cover.

245 Herbivorous fish biomass ranged from approximately 50 to $14,000 \mathrm{~g} / 100 \mathrm{~m}^{2}$ and fleshy

246 macroalgal cover ranged from 0 to $57.5 \%$. There was no correlation between the

247 changes in herbivorous fish biomass and fleshy macroalgal cover for long-term

248 monitoring sites (Spearman, $r_{s}=-0.11, P=0.35$ ). Only $7 \%$ of sites exhibited increased

249 herbivorous fish biomass and decreased macroalgal cover; $35 \%$ of sites displayed

250 decreases in fish biomass and increases in macroalgal cover; almost half of the sites

251 (48 \%) exhibited increases in both herbivorous fish biomass and macroalgal cover; and

$25210 \%$ displayed decreased fish biomass and macroalgal cover (Fig. 3). Across all sites

253 macroalgal cover increased irrespective of initial conditions of herbivorous fish biomass

254 (Spearman, $r_{s}=-0.12, P=0.3 ;$ Fig. $4 \mathrm{~A}$ ) and macroalgae browser biomass (Spearman, $255 \quad r_{s}=-0.21, P=0.3 ;$ Fig. 4B).

256 Considering herbivorous fish feeding preferences based on Bellwood et al. (2004),

257 communities of the Mesoamerican Reef present a mixture of guilds with $24.3 \%$

258 macroalgae browsers by biomass in 2013/14 (19.4\% in 2005/6), $48.4 \%$ (57.3 \%) turf

259 grazers / scrapers and $27.3 \%$ (23.3 \%) bioeroders. Herbivorous fish biomass and

260 macroalgal cover change were broadly similar between macroalgae browsers and 
261 overall results (Fig. 3). Macroalgae browser biomass displayed a slightly greater 262 tendency for increase than overall herbivorous fish biomass, as observed for $61 \%$ of 263 sites compared with $55 \%$, and site-level changes in these were correlated (Spearman, $\left.264 r_{s}=0.70, P<0.001\right)$

265 Geographically, the principal trend was for increasing fleshy macroalgal cover and 266 herbivorous fish biomass in Mexico and northern Belize, including the atolls of Turneffe 267 and Lighthouse Reef, but for increasing fleshy macroalgal cover and decreasing 268 herbivorous fish biomass to the south in south-central and southern Belize, Glover's 269 Reef, Guatemala and Cayos Cochinos, Honduras (Fig. 3). However, the Bay Islands of 270 Honduras were exceptions to this broad north-to-south trend with Guanaja island 271 displaying the highest proportion of sites with increasing herbivorous fish biomass and 272 decreasing macroalgal cover. The only other three sites that experienced increasing 273 herbivorous fish biomass and decreasing macroalgal cover were located at Isla Mujeres 274 and Puerto Morelos in Mexico, and San Pedro in Belize.

275 Of the 85 long-term monitoring sites, 12 sites were located within No Take Zones 276 (NTZs) where all extractive practices are prohibited, 47 were within Marine Protected 277 Areas but not NTZs (MPAs) where reefs benefit from regulation but some extractive 278 practices are permitted, and the remaining 26 were unprotected. The level of protection 279 was observed to affect the initial levels of fleshy macroalgal cover and herbivorous fish 280 biomass, in addition to changes in these over time. In 2005/6, sites within NTZs 281 exhibited similar herbivorous fish biomass and fleshy macroalgal cover to sites located 282 elsewhere within Marine Protected Areas (Mann-Whitney, $U=197, Z=-1.60, P=0.11$; 283 and $U=297, Z=0.28, P=0.78$ respectively; Fig. 5). Protected sites (both MPAs and 
284 NTZs) displayed significantly higher initial macroalgal cover than unprotected sites 285 (Mann-Whitney, both $U \geq 247, Z \geq 2.85$, $P \leq 0.003$; Fig. 5), but only protected sites 286 outside of NTZs exhibited significantly higher initial herbivorous fish biomass than 287 unprotected sites (Mann-Whitney, MPA vs unprotected, $U=819, Z=2.40, P=0.016$;

288 NTZ vs unprotected, $U=161, Z=0.16, P=0.89$; Fig. 5). Along the protection gradient 289 (from unprotected, through MPA to no-take protection), sites appeared to experience a 290 greater increase in herbivorous fish biomass and a lesser increase in macroalgal cover, 291 although the differences were not statistically significant (ANOVA, annual geometric rate 292 of change in fish biomass, $F_{2,82}=0.04, P=0.97$; annual geometric rate of change in 293 macroalgal cover, $\left.F_{2,80}=1.01, P=0.37\right)$.

294 Predicting coral cover change

295 Across all 85 long-term monitoring sites, mean ( \pm s.e.m.) hard coral cover increased 296 significantly from $12.2 \pm 0.8 \%$ in $2005 / 6$ to $15.0 \pm 0.8 \%$ in $2013 / 14$ (Wilcoxon Signed 297 Rank, $Z=-3.81, P<0.001)$. Individual sites displayed varying trajectories with annual 298 changes in coral cover ranging from $-3.1 \%$ to $+2.7 \%$. The optimum linear regression 299 model for the annual absolute change in hard coral cover displayed a modest but 300 significant fit (Adjusted $R^{2}=0.18, F_{7,74}=3.57, P=0.002$ ). The model included seven 301 predictor variables (Table S1), of which four were significant: MPA, country (Honduras), 302 annual logarithmic change in herbivorous fish biomass and initial hard coral cover (Fig. 303 6). Interpreting these significant variables, sites within Marine Protected Areas 304 experienced greater increases in coral cover than unprotected sites; Honduran sites 305 experienced lesser increases in coral cover than other countries; and increases in 306 herbivorous fish biomass corresponded with increases in coral cover. Initial coral cover 
307 was the most significant predictor of coral cover change and therefore in order to further 308 understand its impact, sites were categorised as low (<10\%), medium $(10-20 \%)$ or 309 high ( $\geq 20 \%$ ) initial coral cover. For the 12 long-term monitoring sites with high initial 310 coral cover, mean coral cover decreased over time (mean \pm s.e.m. annual change in 311 coral cover of $-0.6 \pm 0.4 \%$ ), while coral cover increased for sites with lower levels of 312 initial cover (low initial coral cover, $+0.6 \pm 0.1 \%$; medium initial coral cover, $+0.4 \pm 0.2$ $313 \%)$

314 Despite not being selected in the optimum regression model, we further explored the 315 relationship between coral and macroalgal cover due to the long-term ecological shifts 316 reported on many Caribbean reefs. Across all 85 long-term monitoring sites, mean $( \pm$ 317 s.e.m.) macroalgal cover increased significantly from $12.0 \pm 1.1 \%$ in $2005 / 6$ to $24.1 \pm$ $3181.5 \%$ in 2013/14 (Wilcoxon Signed Rank, $Z=-7.07, P<0.001$ ). We observed little or

319 no relationship between coral and macroalgal cover since macroalgal cover consistently 320 increased irrespective of changes in coral cover (Fig. S3). All initial coral cover 321 categories (low (<10\%), medium (10-20\%), and high ( $\geq 20 \%)$ ) experienced increases 322 in fleshy macroalgal cover, and initial macroalgal cover, similarly categorised, did not 323 impact coral cover changes over time (ANOVA, $F_{2,82}=1.10, P=0.34$ ).

\section{Discussion}

326 Substantial changes in the ecological composition of the Mesoamerican Reef were 327 evident in a time span of only nine years. The principal trend is for increasing fleshy 328 macroalgal cover, as observed at $83 \%$ of long-term monitoring sites (Fig. 3). Mean 
329 absolute cover of fleshy macroalgal cover increased by approximately $12 \%$ in the 330 region between 2005 and 2014 (Fig. 2). Mean herbivorous fish biomass remained

331 relatively stable (Fig. 2), although displaying substantial site variation, with $55 \%$ of sites

332 showing an increase in herbivorous fish biomass between 2005 and 2014 (Fig. 3). The

333 scenario of both increasing fleshy macroalgal cover and herbivorous fish biomass was

334 observed at $48 \%$ of the 85 sites while the 'desirable' scenario of increasing herbivorous

335 fish biomass and decreasing macroalgal cover was the least frequent of all four

336 scenarios (Fig. 3). Similar trends were observed for the macroalgae-browsing fish guild

337 (Fig. 3), with site-level macroalgae browser biomass change correlating with overall

338 herbivorous fish biomass change. This suggests that fish herbivory was not a major

339 driver of fleshy macroalgal cover change on the majority of surveyed sites across the

340 Mesoamerican Reef (Fig. 3).

341 The clear pattern of increasing macroalgal cover and stable herbivorous fish biomass

342 on Mesoamerican reefs contrasts with the widely accepted coral reef top-down

343 herbivore control paradigm and management recommendations that advocate

344 increasing herbivory to control fleshy macroalgal cover (Nyström, Folke \& Moberg,

345 2000; McCook, Jompa \& Diaz-Pulido, 2001). This result is consistent with a multi-

346 decadal study reporting that macroalgal cover was not related to long-term parrotfish

347 losses due to fishing in the Philippines (Russ et al., 2015). Furthermore, we found that

348 coral cover on the Mesoamerican Reef was low and unrelated to macroalgal cover.

349 Since both coral cover and reduced herbivory were not responsible for increasing

350 macroalgal cover, external factors may have played a role. For the Mesoamerican Reef

351 region a growing body of evidence shows that rising nutrient levels is a worsening 
352 problem that may be accelerating macroalgal increase. In the Mexican Caribbean

353 previous studies have observed elevated nutrient input to coral reefs due to coastal

354 development (Baker, Rodríguez-Martínez \& Fogel, 2013; Hernández-Terrones et al.,

355 2015) and the subsequent degradation of reef systems (Bozec et al., 2008). In southern

356 Belize and Honduras riverine discharge and escalating reef sediment and nutrient loads

357 associated with urban and agricultural run-off may have played a role in increasing

358 macroalgal cover (Burke \& Sugg, 2006; Carilli et al., 2009; Soto et al., 2009). Our

359 finding that fish herbivory is not responsible for macroalgal cover trends contrasts the

360 results of herbivore exclusion studies, which emphasize the relative importance of

361 herbivory over nutrient availability (McClanahan, Cokos \& Sala, 2002; Burkepile \& Hay,

362 2006, 2009; Sotka \& Hay, 2009). However, contrary to the present study, such

363 experiments tend to be conducted on restricted spatial and temporal scales.

364 Unfortunately, site nutrient data are not widely available for the Mesoamerican Reef,

365 impeding a quantitative exploration of this effect in our analyses.

366 One alternative that could partially explain the rapid increases in fleshy macroalgae

367 across the Mesoamerican Reef is that reef ecosystems passed critical thresholds

368 beyond which herbivorous fishes are unable to control macroalgae due to either

369 excessive algal production and/or insufficient herbivory (Mumby, Hastings \& Edwards,

370 2007). This is particularly relevant given that Caribbean reefs may suffer from

371 insufficient herbivory due to both the limited population recovery of Diadema antillarum

372 subsequent to previous mass mortality and the inability of herbivorous fish to

373 adequately compensate for this loss (McClenachan, 2009; Paddack et al., 2009;

374 Hughes et al., 2010). However, excessive algal production is unlikely on the 
375 Mesoamerican Reef as regional average macroalgal cover increased from only $10 \%$ in $3762005 / 6$ to $22 \%$ in $2013 / 14$ (Fig. 2), values that are likely considerably below ecosystem

377 thresholds for Caribbean reefs (Bruno et al., 2009). Furthermore, an examination of

378 macroalgal change by absolute levels of herbivorous fish biomass revealed increasing

379 fleshy macroalgal cover even for those sites with the highest initial fish biomass (the

380 uppermost deciles possessed average overall herbivorous fish biomass and

381 macroalgae-browsing fish biomass of $9,065 \mathrm{~g} / 100 \mathrm{~m}^{2}$ and $1,762 \mathrm{~g} / 100 \mathrm{~m}^{2}$ respectively;

382 Fig. 4). Although there is little consensus on Caribbean reef herbivorous fish thresholds,

383 a global assessment of the status of coral reef herbivorous fishes identified only 9 of

384132 localities as having herbivorous fish biomass greater than $9,000 \mathrm{~g} / 100 \mathrm{~m}^{2}$,

385 suggesting this to be a high benchmark (Mumby, Hastings \& Edwards, 2007; Edwards

386 et al., 2014). In addition, a negative correlation between Caribbean reef herbivorous fish

387 biomass and fleshy algal biomass has been previously observed with a site maximum of

388 only $7,000 \mathrm{~g} / 100 \mathrm{~m}^{2}$ approximately (Newman et al., 2006).

389 The threshold hypothesis would be particularly relevant if the decline in average

390 herbivorous fish biomass between 2005/6 and 2009/10 resulted in changes in the

391 relative proportion of key functional groups, favouring non-macroalgae-browsing

392 species (Adam et al., 2015b; Fig. 2). However, the relative proportions of the three main

393 herbivorous fish functional groups remained stable during the study period (Fig. S4).

394 Additionally, a close examination of those sites that suffered the greatest herbivorous

395 fish biomass losses between 2005 and 2009 revealed that these sites experienced

396 similar macroalgal growth from 2009 to 2014 compared with other sites (Fig. S5). This

397 suggests that the observed rapid increases in fleshy macroalgae are not due to 
398 Mesoamerican reefs passing critical thresholds of excessive algal production and/or 399 insufficient herbivory.

400 Fish populations may impact benthic communities indirectly through mediation of 401 benthic competition. Sponges are a major component of Caribbean coral reef benthos 402 that compete for space with corals and macroalgae (Loh et al., 2015). Sponges' 403 competitive superiority over corals is well documented and likely due to a number of 404 mechanisms including shading, smothering and allelopathy (Porter \& Targett, 1988; Loh 405 et al., 2015). Overfishing of spongivorous parrotfishes and angelfishes has been shown 406 to alter ecosystem dynamics through the alleviation of predation pressure on sponges 407 (Loh \& Pawlik, 2014; Loh et al., 2015). Therefore, it is likely that at sites with high 408 parrotfish biomass, spongivory will control benthic sponge cover, indirectly benefiting 409 macroalgal and coral communities via reduced benthic competition. Unfortunately we 410 could not further explore the role of sponges in shaping benthic interactions as the 411 survey protocol does not focus on producing reliable sponge cover information (Lang et 412 al 2010).

413 Coral recovery on the Mesoamerican Reef was related to MPA protection and 414 increasing biomass of herbivorous fish, but not via the expected mechanism of 415 macroalgal declines through fish herbivory. Alternative mechanisms for the effect of 416 protection on reef corals are less well studied, but may include reduced disease 417 prevalence, and diminished physical reef damage through regulation of fishing and 418 recreational diving practices (Hasler \& Ott, 2008; Lamb et al., 2015). Replenished fish 419 communities inside marine reserves can also drive coral recovery through ecological 420 processes not necessarily linked with herbivory. For example, trophically diverse fish 
421 communities inside marine reserves have been shown to ameliorate coral disease

422 prevalence, although the pathways through which this takes place remain unclear

423 (Raymundo et al., 2009). Alternatively, coral cover and complexity may influence

424 herbivorous fish populations, rather than vice-versa, or the relationship may be purely

425 correlative with both indicators being driven by marine protection (Halpern, 2003; Selig

426 \& Bruno, 2010; Alvarez-Filip, Gill \& Dulvy, 2011).

427 Reef protection has a positive impact on herbivorous fish biomass and coral cover,

428 although fleshy macroalgal cover continued to increase at most sites. Although

429 protection impacted herbivorous fish biomass and macroalgal cover trajectories (Fig. 5),

430 initial differences between protected and unprotected sites tend to persist, with

431 unprotected sites continuing to display lower macroalgal cover. This may be attributable

432 to reserve age, as protected sites were located within reserves designated in $2003( \pm 1$

433 year) on average, and studies have shown that protection influence may be subject to a

434 lag effect (Selig \& Bruno, 2010; Babcock et al., 2010). Furthermore, the use of

435 protection categories (No Take Zones (NTZs), Marine Protected Areas but not NTZs,

436 and unprotected) is a coarse measure of the actual range of protection and fishing

437 pressure experienced at sites. Additionally, local conditions and reserve regulations

438 often obfuscate protection impact due to variability of internal factors such as reef

439 community structure and enforcement level, and external impacts including local

440 stressors and global climate change (Mora et al., 2006; McClanahan et al., 2006; Selig,

441 Casey \& Bruno, 2012). Finally, trophic effects may play a role since trophic cascades

442 are expected when populations of large predators are enhanced due to protection

443 (Estes et al., 2011). The protection of piscivores, for example, may result in herbivore 
444 reduction and consequently elevated macroalgal growth inside marine reserves.

445 However, studies that explored this question have found that changes in predator

446 populations do not discernibly influence, or are even positively correlated with the

447 density, size, and biomass of herbivorous fishes, suggesting that top-down forces may

448 not play a strong role in regulating large-bodied herbivorous fish on coral reefs (Mumby

449 et al., 2006; Houk \& Musburger, 2013; Rizzari, Bergseth \& Frisch, 2015).

450

451 Conclusions

452 Despite the long-term reduction of herbivory capacity reported across the Caribbean, 453 the Mesoamerican Reef displayed relatively low macroalgal cover at the onset of this 454 study. Subsequently, during the last decade, fleshy macroalgal cover increased rapidly 455 on Mesoamerican reefs. Herbivorous fish populations were not responsible for this 456 trend, contrasting the coral reef top-down herbivore control paradigm and implicating 457 the role of external factors in making environmental conditions more favourable for 458 algae. Increasing macroalgal cover typically suppresses ecosystem services and leads 459 to degraded reef systems. Consequently, policy makers and local managers should 460 consider complementary protection measures such as watershed management, in 461 addition to herbivorous fish protection, in order to arrest this trend.

462

463 Acknowledgments 
464 The authors recognize the invaluable efforts of Healthy Reefs Initiative (HRI) partner

465 organizations and individual field researchers who collaborated over the years in

466 collecting the data. Data contributors are listed in HRI Report Cards and supplemental

467 reports, available at www.healthyreefs.org. In particular lan Drysdale, Marisol Rueda,

468 Ana Giro and Roberto Pott are recognised for coordinating field surveys, training and

469 data entry. The HRI database is processed and managed in conjunction with Ken Marks

470 and Judith Lang. Our manuscript was significantly improved by insightful comments

471 from R. Iglesias-Prieto, J. Bruno and one anonymous reviewer.

\section{References}

Adam TC., Schmitt RJ., Holbrook SJ., Brooks AJ., Edmunds PJ., Carpenter RC., Bernardi G. 2011. Herbivory, connectivity, and ecosystem resilience: response of a coral reef to a large-scale perturbation. PLoS One 6:e23717.

Adam TC., Burkepile DE., Ruttenberg BI., Paddack MJ. 2015a. Herbivory and the resilience of Caribbean coral reefs: knowledge gaps and implications for management. Marine Ecology Progress Series 520:1-20.

479

480

Adam TC., Kelley M., Ruttenberg BI., Burkepile DE. 2015b. Resource partitioning along multiple niche axes drives functional diversity in parrotfishes on Caribbean coral reefs. Oecologia 179:1173-1185.

Alvarez-Filip L., Dulvy NK., Côté IM., Watkinson AR., Gill JA. 2011. Coral identity underpins architectural complexity on Caribbean reefs. Ecological Applications 21:2223-2231.

Álvarez-Filip L., Gil I. 2006. Effects of Hurricanes Emily and Wilma on coral reefs in Cozumel, Mexico. Coral Reefs 25:583.

Alvarez-Filip L., Gill JA., Dulvy NK. 2011. Complex reef architecture supports more small-bodied fishes and longer food chains on Caribbean reefs. Ecosphere 2:118.

Andréfouët S., Kramer P., Torres-Pulliza D., Joyce KE., Hochberg EJ., Garza-Pérez R., Mumby PJ., Riegl B., Yamano H., White WH., Zubia M., Brock JC., Phinn SR., Naseer A., Hatcher BG., Muller-Karger FE. 2003. Multi-site evaluation of IKONOS data for classification of tropical coral reef environments. Remote Sensing of Environment 88:128-143.

Babcock RC., Shears NT., Alcala AC., Barrett NS., Edgar GJ., Lafferty KD., McClanahan TR., Russ GR. 2010. Decadal trends in marine reserves reveal differential rates of change in direct and indirect effects. Proceedings of the National Academy of Sciences of the United States of America 107:18256-18261.

Baker DM., Rodríguez-Martínez RE., Fogel ML. 2013. Tourism's nitrogen footprint on a Mesoamerican coral reef. Coral Reefs 32:691-699. 
499

500

501

502

503

504

505

506

507

508

509

510

511

512

513

514

515

516

517

518

519

520

521

522

523

524

525

526

527

Bozec YM., Acosta-González G., Núñez-Lara E., Arias-González JE. 2008. Impacts of coastal development on ecosystem structure and function of Yucatan coral reefs, Mexico. Proceedings of the 11th International Coral Reef Symposium:691-695.

Bruno JF., Sweatman H., Precht WF., Selig ER., Schutte VGW. 2009. Assessing evidence of phase shifts from coral to macroalgal dominance on coral reefs. Ecology 90:1478-1484.

Burke L., Sugg Z. 2006. Hydrologic Modeling of Watersheds Discharging Adjacent to the Mesoamerican Reef. Washington, D.C.

Burkepile DE., Hay ME. 2006. Herbivore vs. nutrient control of marine primary producers: context-dependent effects. Ecology 87:3128-3139.

Burkepile DE., Hay ME. 2008. Herbivore species richness and feeding complementarity affect community structure and function on a coral reef. Proceedings of the National Academy of Sciences of the United States of America 105:16201-16206.

Burkepile DE., Hay ME. 2009. Nutrient versus herbivore control of macroalgal community development and coral growth on a Caribbean reef. Marine Ecology Progress Series 389:71-84.

Burkepile DE., Hay ME. 2011. Feeding complementarity versus redundancy among herbivorous fishes on a Caribbean reef. Coral Reefs 30:351-362.

Carassou L., Léopold M., Guillemot N., Wantiez L., Kulbicki M. 2013. Does herbivorous fish protection really improve coral reef resilience? A case study from New Caledonia (South Pacific). PLoS One 8:e60564.

Carilli JE., Prouty NG., Hughen KA., Norris RD. 2009. Century-scale records of land-based activities recorded in Mesoamerican coral cores. Marine Pollution Bulletin 58:1835-1842.

Carpenter RC. 1990. Mass mortality of Diadema antillarum. Il. Effects on population densities and grazing intensity of parrotfishes and surgeonfishes. Marine Biology 104:79-86.

Côté IM., Gill JA., Gardner TA., Watkinson AR. 2005. Measuring coral reef decline through meta-analyses. Philosophical Transactions of the Royal Society of London B 360:385-395.

Edwards CB., Friedlander AM., Green AG., Hardt MJ., Sala E., Sweatman HP., Williams ID., Zgliczynski B., Sandin SA., Smith JE. 2014. Global assessment of the status of coral reef herbivorous fishes: evidence for fishing effects. Proceedings of The Royal Society of London B 281:20131835.

Estes JA., Terborgh J., Brashares JS., Power ME., Berger J., Bond WJ., Carpenter SR., Essington TE., Holt RD., Jackson JBC., Marquis RJ., Oksanen L., Oksanen T., Paine RT., Pikitch EK., Ripple WJ., Sandin SA., Scheffer M., Schoener TW., Shurin JB., Sinclair ARE., Soulé ME., Virtanen R., Wardle DA. 2011. Trophic downgrading of planet Earth. Science 333:301-306.

Ferrari R., Gonzalez-Rivero M., Ortiz JC., Mumby PJ. 2012. Interaction of herbivory and seasonality on the dynamics of Caribbean macroalgae. Coral Reefs 31:683-692.

Graham NAJ., Jennings S., MacNeil MA., Mouillot D., Wilson SK. 2015. Predicting climate-driven regime shifts versus rebound potential in coral reefs. Nature 518:94-97.

Guarderas AP., Hacker SD., Lubchenco J. 2011. Ecological effects of marine reserves in Latin America and the Caribbean. Marine Ecology Progress Series 429:219-225.

Halpern BS. 2003. The impact of marine reserves: do reserves work and does reserve size matter? Ecological Applications 13:S117-S137.

Hasler H., Ott JA. 2008. Diving down the reefs? Intensive diving tourism threatens the reefs of the northern Red Sea. Marine Pollution Bulletin 56:1788-1794.

Hay ME. 1997. The ecology and evolution of seaweed-herbivore interactions on coral reefs. Coral Reefs 16:S67S76.

Hay ME., Taylor PR. 1985. Competition between herbivourous fishes and urchins on Caribbean reefs. Oecologia 65:591-598.

Hernández-Terrones LM., Null KA., Ortega-Camacho D., Paytan A. 2015. Water quality assessment in the Mexican Caribbean: impacts on the coastal ecosystem. Continental Shelf Research 102:62-72.

Houk P., Musburger C. 2013. Trophic interactions and ecological stability across coral reefs in the Marshall Islands. 
Marine Ecology Progress Series 488:23-34.

Hughes TP. 1994. Catastrophes, phase shifts and large-scale degradation of a Caribbean coral reef. Science 265:1547-1551.

Hughes TP., Rodrigues MJ., Bellwood DR., Ceccarelli D., Hoegh-Guldberg O., McCook L., Moltschaniwskyj N., Pratchett MS., Steneck RS., Willis B. 2007. Phase shifts, herbivory, and the resilience of coral reefs to climate change. Current Biology 17:360-365.

Hughes TP., Graham NAJ., Jackson JBC., Mumby PJ., Steneck RS. 2010. Rising to the challenge of sustaining coral reef resilience. Trends in Ecology and Evolution 25:633-642.

Ilves KL., Kellogg LL., Quattrini AM., Chaplin GW., Hertler H., Lundberg JG. 2011. Assessing 50-year change in Bahamian reef fish assemblages: evidence for community response to recent disturbance? Bulletin of Marine Science 87:567-588.

Jackson JB., Kirby MX., Berger WH., Bjorndal KA., Botsford LW., Bourque BJ., Bradbury RH., Cooke R., Erlandson J., Estes J a., Hughes TP., Kidwell S., Lange CB., Lenihan HS., Pandolfi JM., Peterson CH., Steneck RS., Tegner MJ., Warner RR. 2001. Historical overfishing and the recent collapse of coastal ecosystems. Science 293:629-637.

Jackson JBC., Donovan MK., Cramer KL., Lam V. 2014. Status and Trends of Caribbean Coral Reefs: $1970-2012$. Gland, Switzerland: Global Coral Reef Monitoring Network, IUCN.

Karr KA., Fujita R., Halpern BS., Kappel C V., Crowder L., Selkoe KA., Alcolado PM., Rader D. 2015. Thresholds in Caribbean coral reefs: implications for ecosystem-based fishery management. Journal of Applied Ecology $52: 402-412$.

Kramer PA. 2003. Synthesis of coral reef health indicators for the western Atlantic: results of the AGRRA program (1997-2000). Atoll Research Bulletin 496:1-58.

Kramer P., McField M., Álvarez Filip L., Drysdale I., Rueda Flores M., Giró A., Pott R. 2015. 2015 Report Card for the Mesoamerican Reef. Healthy Reefs Initiative. Available at http://www.healthyreefs.org.

Lamb JB., Williamson DH., Russ GR., Willis BL. 2015. Protected areas mitigate diseases of reef-building corals by reducing damage from fishing. Ecology 96:2555-2567.

Lang JC., Marks KW., Kramer PA., Kramer PR., Ginsburg RN. 2010. AGRRA Protocols Version 5.4. The Atlantic and Gulf Rapid Reef Assessment (AGRRA) Program.

Lessios HA., Robertson DR., Cubit JD. 1984. Spread of Diadema mass mortality through the Caribbean. Science 226:335-337.

Lester SE., Halpern BS., Grorud-Colvert K., Lubchenco J., Ruttenberg BI., Gaines SD., Airamé S., Warner RR. 2009. Biological effects within no-take marine reserves: a global synthesis. Marine Ecology Progress Series 384:3346.

Lirman D. 2001. Competition between macroalgae and corals: effects of herbivore exclusion and increased algal biomass on coral survivorship and growth. Coral Reefs 19:392-399.

Lirman D., Biber P. 2000. Seasonal dynamics of macroalgal communities of the Northern Florida Reef Tract. Botanica Marina 43:305-314.

Loh T-L., McMurray SE., Henkel TP., Vicente J., Pawlik JR. 2015. Indirect effects of overfishing on Caribbean reefs: sponges overgrow reef-building corals. PeerJ 3:e901.

Loh T-L., Pawlik JR. 2014. Chemical defenses and resource trade-offs structure sponge communities on Caribbean coral reefs. Proceedings of the National Academy of Sciences of the United States of America 111:4151-4156.

McClanahan TR., Marnane MJ., Cinner JE., Kiene WE. 2006. A comparison of marine protected areas and alternative approaches to coral-reef management. Current Biology 16:1408-1413.

McClenachan L. 2009. Historical declines of goliath grouper populations in South Florida, USA. Endangered Species Research 7:175-181.

McCook LJ., Jompa J., Diaz-Pulido G. 2001. Competition between corals and algae on coral reefs: a review of evidence and mechanisms. Coral Reefs 19:400-417.

McManus JW., Polsenberg JF. 2004. Coral-algal phase shifts on coral reefs: ecological and environmental aspects. 
Progress in Oceanography 60:263-279.

596

597

598

599

600

601

602

603

604

605

606

607

608

609

610

611

612

613

614

615

616

617

618

619

620

621

622

623

624

625

626

627

628

629

630

631

632

633

634

635

636

637

638

639

640

641

642

Mora C., Andrèfouët S., Costello MJ., Kranenburg C., Rollo A., Veron J., Gaston KJ., Myers RA. 2006. Coral reefs and the global network of Marine Protected Areas. Science 312:1750-1751.

Mumby PJ., Dahlgren CP., Harborne AR., Kappel C V., Micheli F., Brumbaugh DR., Holmes KE., Mendes JM., Broad K., Sanchirico JN., Buch K., Box S., Stoffle RW., Gill AB. 2006. Fishing, trophic cascades, and the process of grazing on coral reefs. Science 311:98-101.

Mumby PJ., Hastings A., Edwards HJ. 2007. Thresholds and the resilience of Caribbean coral reefs. Nature 450:98101.

Newman MJH., Paredes GA., Sala E., Jackson JBC. 2006. Structure of Caribbean coral reef communities across a large gradient of fish biomass. Ecology Letters 9:1216-1227.

Nyström M., Folke C., Moberg F. 2000. Coral reef disturbance and resilience in a human-dominated environment. Trends in Ecology \& Evolution 15:413-417.

Paddack MJ., Reynolds JD., Aguilar C., Appeldoorn RS., Beets J., Burkett EW., Chittaro PM., Clarke K., Esteves R., Fonseca AC., Forrester GE., Friedlander AM., García-Sais J., González-Sansón G., Jordan LKB., McClellan DB., Miller MW., Molloy PP., Mumby PJ., Nagelkerken I., Nemeth M., Navas-Camacho R., Pitt J., Polunin NVC., Reyes-Nivia MC., Robertson DR., Rodríguez-Ramírez A., Salas E., Smith SR., Spieler RE., Steele MA., Williams ID., Wormald CL., Watkinson AR., Côté IM. 2009. Recent region-wide declines in Caribbean reef fish abundance. Current Biology 19:590-595.

Perry CT., Steneck RS., Murphy GN., Kench PS., Edinger EN., Smithers SG., Mumby PJ. 2015. Regional-scale dominance of non-framework building corals on Caribbean reefs affects carbonate production and future reef growth. Global Change Biology 21:1153-1164.

Porter JW., Targett NM. 1988. Allelochemical interactions between sponges and corals. Biological Bulletin 175:230239.

R Core Team. 2014.R: A language and environment for statistical computing. Available at http://www.r-project.org.

Rasher DB., Stout EP., Engel S., Kubanek J., Hay ME. 2011. Macroalgal terpenes function as allelopathic agents against reef corals. Proceedings of the National Academy of Sciences of the United States of America 108:17726-17731.

Rasher DB., Hoey AS., Hay ME. 2013. Consumer diversity interacts with prey defenses to drive ecosystem function. Ecology 94:1347-1358.

Raymundo LJ., Halford AR., Maypa AP., Kerr AM. 2009. Functionally diverse reef-fish communities ameliorate coral disease. Proceedings of the National Academy of Sciences of the United States of America 106:17067-17070.

Rizzari JR., Bergseth BJ., Frisch AJ. 2015. Impact of conservation areas on trophic interactions between apex predators and herbivores on coral reefs. Conservation Biology 29:418-429.

Russ GR., Questel S-LA., Rizzari JR., Alcala AC. 2015. The parrotfish-coral relationship: refuting the ubiquity of a prevailing paradigm. Marine Biology 162:2029-2045.

Schutte VGW., Selig ER., Bruno JF. 2010. Regional spatio-temporal trends in Caribbean coral reef benthic communities. Marine Ecology Progress Series 402:115-122.

Selig ER., Bruno JF. 2010. A global analysis of the effectiveness of Marine Protected Areas in preventing coral loss. PLoS One 5:e9278.

Selig ER., Casey KS., Bruno JF. 2012. Temperature-driven coral decline: the role of marine protected areas. Global Change Biology 18:1561-1570.

Smith JE., Hunter CL., Smith CM. 2010. The effects of top-down versus bottom-up control on benthic coral reef community structure. Oecologia 163:497-507.

Soto I., Andréfouët S., Hu C., Muller-Karger FE., Wall CC., Sheng J., Hatcher BG. 2009. Physical connectivity in the Mesoamerican Barrier Reef System inferred from 9 years of ocean color observations. Coral Reefs 28:415425.

Steneck RS., Dethier MN. 1994. A functional group approach to the structure of algal-dominated communities. Oikos 69:476-498. 


\section{Figure 1 (on next page)}

Relationship between changes in herbivorous fish biomass and benthic fleshy macroalgal cover.

Possible cause-and-effect scenarios with external drivers are postulated for each quadrant. Fish and algae graphics by Diana Kleine and Tracey Saxby (IAN Image Library, Integration and Application Network, University of Maryland Center for Environmental Science, http://ian.umces.edu/imagelibrary). 


\section{Cover Change}

\section{Extraction / habitat loss}

Algae-adverse conditions

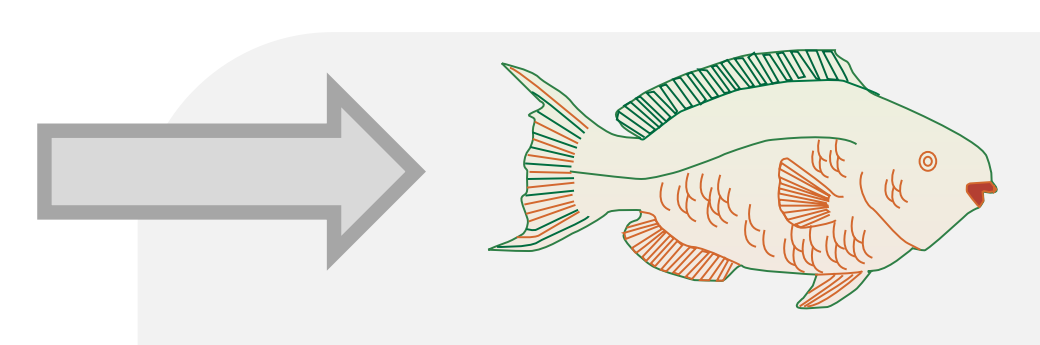

Reduced herbivory
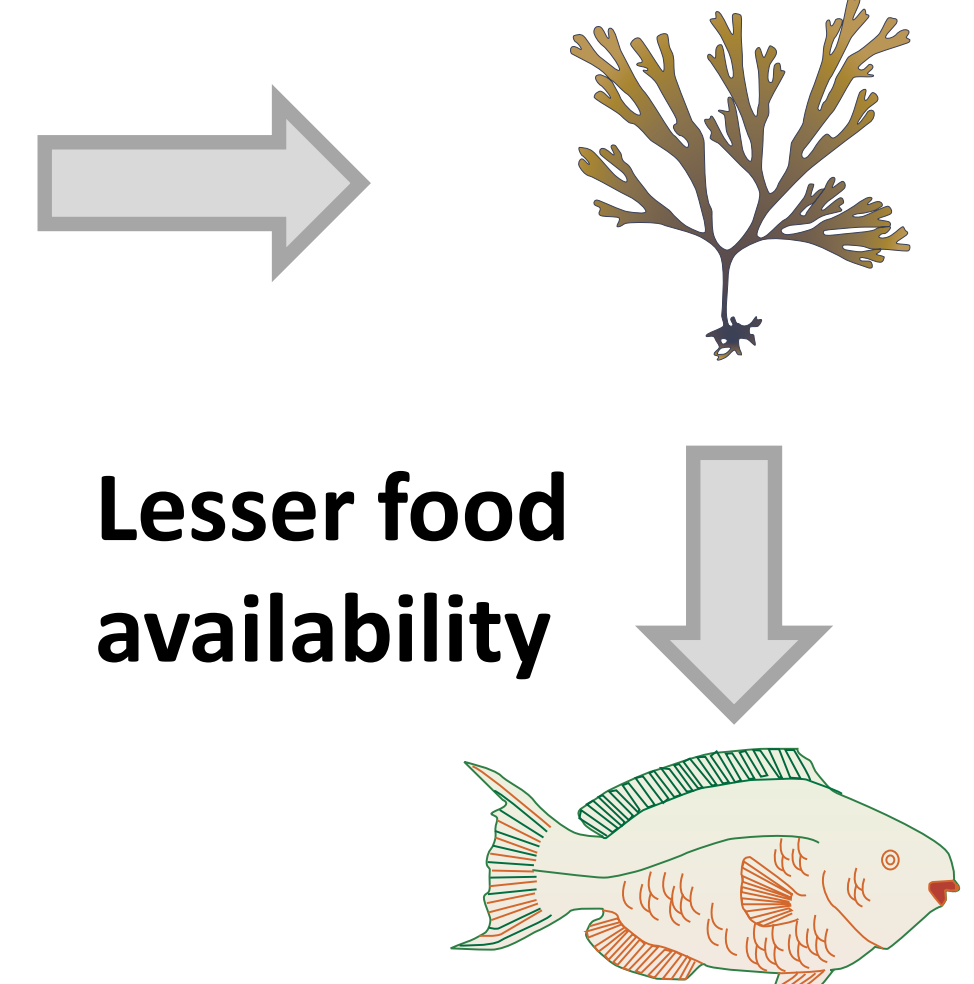
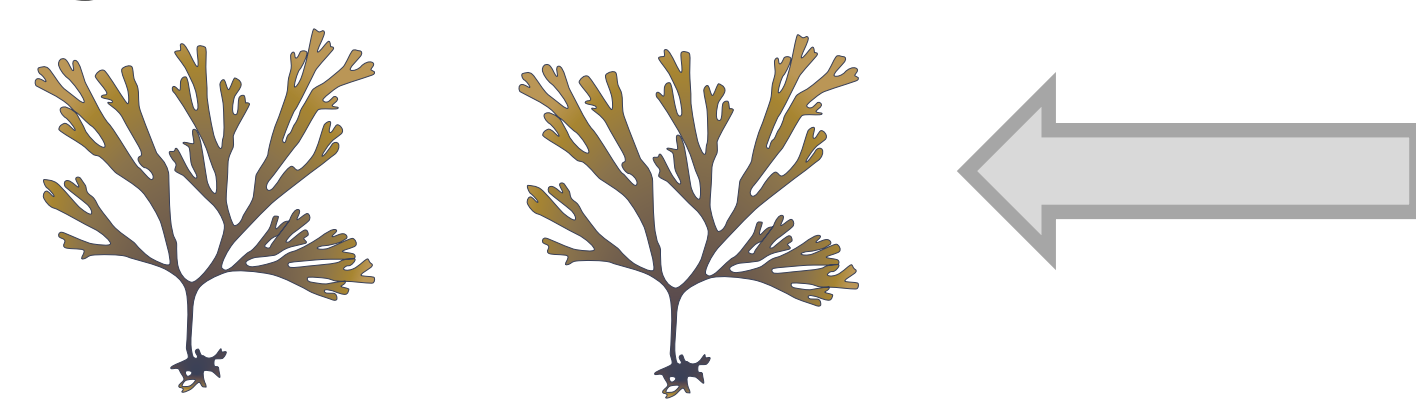

Algae-favourable conditions (e.g. nutrient enrichment)
Herbivorous Fish Biomass Change

Protection /

habitat availability
Increased herbivory 
Figure 2 (on next page)

Temporal trend in mean herbivorous fish biomass and benthic fleshy macroalgal cover on the Mesoamerican Reef.

Mean ( \pm s.e.m.) values are shown for all 43 sites surveyed repeatedly in each monitoring period (2005/2006, 2009/2010, 2011/2012 and 2013/2014). Similar trends were observed for all sites surveyed in consecutive monitoring periods (Fig. S1). 


\section{Figure 3 (on next page)}

Long-term herbivorous fish and benthic fleshy macroalgal cover trends on the Mesoamerican Reef.

Map and graphs indicating relationship between changes in overall and macroalgae-browsing herbivorous fish biomass and fleshy macroalgal cover from first (2005 or 2006) to last (2013 or 2014) year for all (85) long-term monitoring sites with $\geq 7$ years' history. Map indicates Healthy Reef Initiative regions within countries and locates sites by the relationship between changes in herbivorous fish biomass and fleshy macroalgal cover (Kramer et al., 2015). Inset graphs separately indicate the relationship between changes in herbivorous fish biomass and fleshy macroalgal cover, and macroalgae-browsing herbivorous fish biomass and fleshy macroalgal cover. For inset graphs, each circle represents the sites for that quadrant and circle position reflects mean site-level annual geometric rates of change. Circle area represents proportion of sites in that quadrant (also labelled). All (85) sites with $\geq 7$ years' of history are plotted in order to provide long-term trends, although the equivalent analysis for sites with $\geq 8$ years' of history produced similar results (Fig. S2). 


\section{Figure 4 (on next page)}

Effect of initial herbivorous fish biomass on fleshy macroalgal cover on the Mesoamerican Reef.
A) Mean ( \pm s.e.m.) benthic macroalgal cover in 2005/6 (green symbols) and 2013/14 (red symbols) by initial level of overall herbivorous fish biomass, for all (85) long-term monitoring sites. Sites divided into 10 categories based on initial overall herbivorous fish biomass deciles. B) Mean ( \pm s.e.m.) benthic macroalgal cover in 2005/6 (green symbols) and 2013/14 (red symbols) by initial macroalgae browser biomass, for all (85) long-term monitoring sites. Sites divided into 10 categories based on initial macroalgae browser biomass deciles. 
Figure $\mathbf{5}$ (on next page)

Effect of protection on herbivorous fish biomass and fleshy macroalgal cover on the Mesoamerican Reef.

Mean ( \pm s.e.m.) herbivorous fish biomass and benthic macroalgal cover in 2005/6 (green symbols) and 2013/14 (red symbols) by level of protection, for all (85) long-term monitoring sites. Unprotected $=$ sites outside Marine Protected Areas $(n=26)$, MPA $=$ sites inside Marine Protected Areas but not within No Take Zones $(n=47), N T Z=$ sites within No Take Zones within Marine Protected Areas $(n=12)$. 


\section{Figure $\mathbf{6}$ (on next page)}

Prediction of coral cover change on the Mesoamerican Reef.

Standardised regression coefficients for independent variables in AIC-selected optimum model of annual absolute change in hard coral cover from 2005/6 to 2013/14 for all long-term monitoring sites. MPA and NTZ are binary indicators of the location of sites within a Marine Protected Area or No Take Zone, respectively. Mexico and Honduras are binary indicators of the location of sites within those countries. Coefficients reflect the number of standard deviations change in the dependent variable for a one standard deviation increase in each independent variable, while controlling for all other independent variables. Error bars are coefficient standard errors. Significant variables (in non-standardised regression) are highlighted $(* * * 0.001$ level, $* 0.05$ level). 


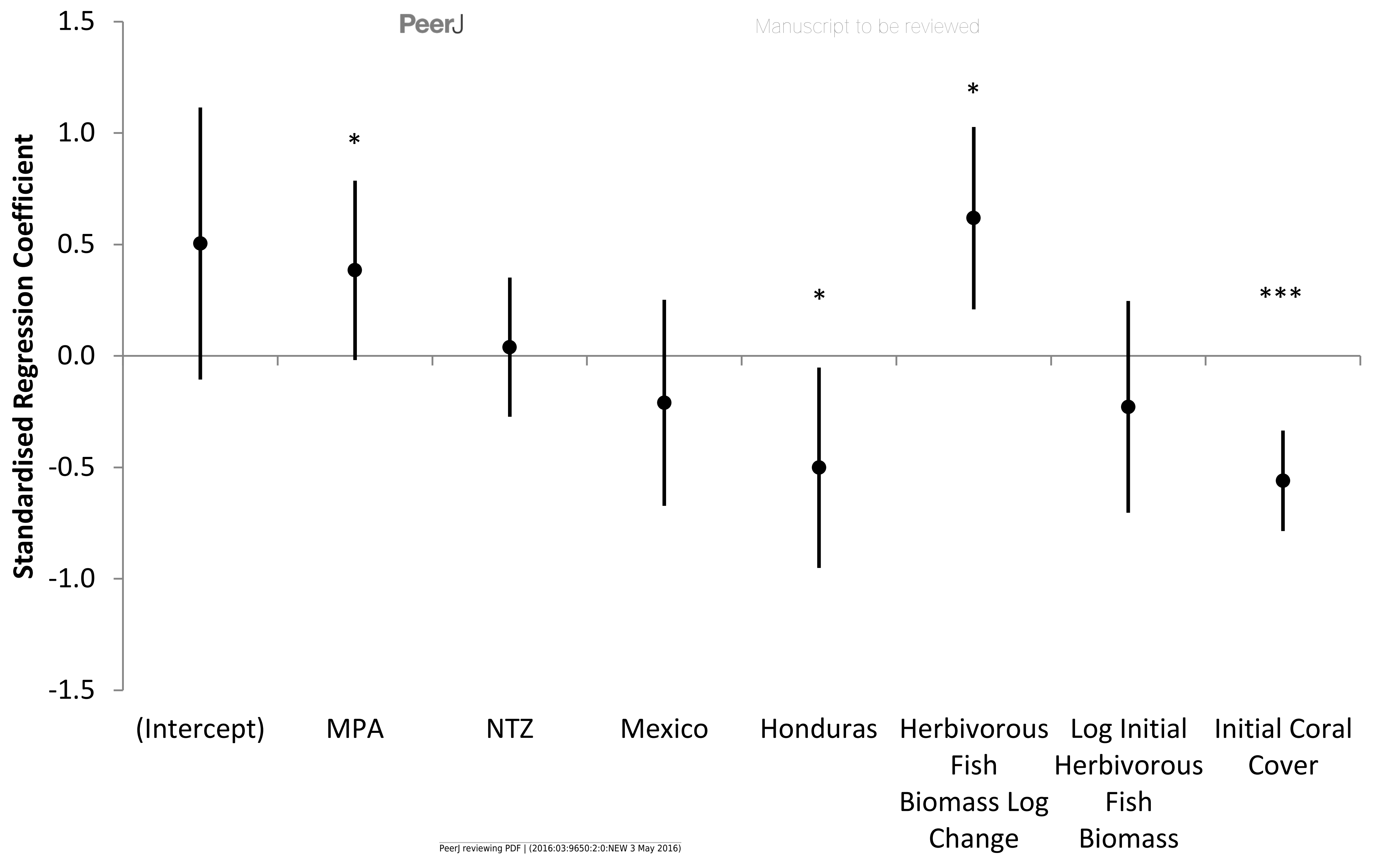

